\title{
Sobrevivência de fungos fitopatogênicos habitantes do solo, em microcosmo, simulando solarização com prévia incorporação de materiais orgânicos
}

\author{
Márcia Michelle de Queiroz Ambrósioํㅜ, César Júnior Bueno², Carlos Roberto Padovani ${ }^{3}$ \& Nilton Luiz de Souza ${ }^{4}$
}

${ }^{1}$ UFCG/CCTA/Unidade Acadêmica de Agronomia e Tecnologia de Alimentos, Pombal-PB; ${ }^{2}$ APTA/IB-CEIB. Rodovia Heitor Penteado, Km 03, Jardim das Palmeiras, Caixa Postal 70, 13001-970, Campinas-SP; ${ }^{3}$ IBB/UNESP, Depto. Bioestatística, Botucatu - SP; ${ }^{4}$ FCA/UNESP, Depto. Produção Vegetal/Defesa Fitossanitária, CP. 237, 18603-970, Botucatu-SP - In memorian.

Autor para correspondência: Márcia Michelle de Queiroz Ambrósio

Data de chegada: 10/05/2007. Aceito para publicação em: 09/05/2008

\section{RESUMO}

Ambrósio, M.M.Q.; Bueno, C.J.; Padovani, C.R. \& Souza, N.L. Sobrevivência de fungos fitopatogênicos habitantes do solo, em microcosmo, simulando solarização com prévia incorporação de materiais orgânicos. Summa Phytopathologica, v.35, n.1, p.20-25, 2009.

Os fungos fitopatogênicos habitantes do solo podem sobreviver por vários anos nesse ambiente por meio de estruturas de resistência, causando perdas em muitas culturas, por vezes, inviabilizando o pleno aproveitamento de vastas áreas agrícolas. O uso de materiais orgânicos no solo consorciado com a técnica de solarização propicia a retenção de compostos voláteis fungitóxicos emanados da rápida degradação dos materiais e que são letais a vários fitopatógenos. O objetivo deste experimento foi à prospecção de novos materiais orgânicos que produzissem voláteis fungitóxicos capazes de controlar fungos fitopatogênicos habitantes do solo, em condições de associação com a simulação da técnica de solarização (microcosmo). Portanto, o presente trabalho consistiu de seis tratamentos (Solarizado; Solarizado+Brócolos;
Solarizado+Eucalipto; Solarizado+Mamona; Solarizado+Mandioca e Laboratório) e cinco períodos ( $0,7,14,21$ e 28 dias) para avaliar a sobrevivência de quatro fungos de solo (Fusarium oxysporum f. sp. lycopersici Raça 2; Macrophomina phaseolina; Rhizoctonia solani AG-4 HGI e Sclerotium rolfsii). Em cada uma das duas câmaras de vidro (microcosmo) por dia avaliado continha uma bolsa de náilon contendo as estruturas de resistência de cada fitopatógeno. Estruturas dos fitopatógenos foram mantidas também em condições de laboratório como referencial de controle. Todos os materiais quando associados à simulação da solarização propiciaram o controle de todos os fitopatógenos estudados, entretanto, foi observado variação no controle dos fungos. O tratamento que apenas simulou a solarização não controlou nenhum fitopatógeno.

Palavras-chave adicionais: controle alternativo, decomposição acelerada, fungos fitopatogênicos, estruturas de resistência.

\section{ABSTRACT}

Ambrósio, M.M.Q.; Bueno, C.J.; Padovani, C.R. \& Souza, N.L. Survival of soilborne plant pathogenic fungi in soil solarization simulation (microcosm) associated with the incorporation of organic materials. Summa Phytopathologica, v.35, n.1, p.20-25, 2009.

Soilborne phytopathogenic fungi can survive for several years in soil through resistance structures and it causes losses in several crops making unfeasible vast agricultural areas. Organic materials associated with soil solarization helps the retention of volatile fungitoxic compounds from the degradation of materials which are lethal to several soil fungi. The objective of this experiment was to search for new organic materials that produce volatile fungitoxic compounds capable to control the resistance structures produced by the soilborne phytopathogenic fungi but in conditions of association with simulation of soil solarization (microcosm). The present work consisted of six treatments (Solarization; Solarization+brocollis; Solarization + eucalyptus; Solarization+castor plants; Solarization + cassava and
Laboratory) and five periods (0, 7, 14, 21 and 28 days) to evaluate the survival of four soil fungi (Fusarium oxysporum f. sp. lycopersici race 2; Macrophomina phaseolina; Rhizoctonia solani AG-4 HGI and Sclerotium rolfsii). A nylon bag containing structures of each pathogen was placed in each one of the two glass cameras (microcosm) for each evaluated period. Structures of the fungi were also maintained in laboratory conditions as the check treatment. All materials when associated the simulation of the soil solarization gave the best control of the structures of all the studied soilborne phytopathogenic fungi. However, variation was observed in the control of the fungi. The treatment which only simulated the solarization did not control any fungus.

Keywords: alternative control, accelerated fermentation, soilborne phytopathogenic fungi, and resistance structures.

A solarização do solo é uma das alternativas de controle para vários patógenos habitantes de solo e a inativação destes é feita basicamente por altas temperaturas acumuladas no solo durante o tratamento (22). A existência de microrganismos termotolerantes dificulta esta prática, haja visto que estes organismos necessitam de grandes períodos de exposição a altas temperaturas para serem inativados. A incorporação de material orgânico previamente a colocação do plástico, vem sendo estudada com o intuito de promover o aprisionamento de gases fungitóxicos provenientes da decomposição acelerada, conferindo assim um efeito aditivo à solarização $(1,2,8)$. Este efeito propicia a inativação de fitopatógenos termófilos, bem como implica na redução do período de imobilização da área. Poucos materiais foram relatados como promissores para o controle de patógenos de solo quando utilizados conjuntamente com a técnica de solarização.

Dessa forma, o objetivo do presente trabalho consistiu na 
prospecção de novos materiais orgânicos que produzissem voláteis fungitóxicos capazes de controlar fungos fitopatogênicos veiculados pelo solo, em condições de simulação da técnica de solarização. Para facilitar essa prospecção, o experimento foi feito em condições de microcosmo (câmara de vidro) que simula a solarização do solo em condição de estufa tipo demanda biológica de oxigênio (BOD).

\section{MATERIAL E MÉTODOS}

Foram realizados dois experimentos, sendo o segundo uma repetição do primeiro. Os ensaios foram conduzidos nas dependências do Departamento de Produção Vegetal (DPV)/Defesa Fitossanitária da Faculdade de Ciências Agronômicas (FCA) - UNESP, BotucatuSP.

A simulação da solarização, em condições de laboratório, foi feita em microcosmo, conforme metodologia descrita por Bueno et al. (4). As câmaras de vidro, mantidas em estufa tipo BOD, foram submetidas à temperatura de $37 \pm 2^{\circ} \mathrm{C}$ durante quatro semanas.

Foram estudados quatro fungos fitopatogênicos habitantes do solo (Fusarium oxysporum f. sp. lycopersici Raça 2; Macrophomina phaseolina; Rhizoctonia solani GA-4 HGI e Sclerotium rolfsii) e quatro materiais orgânicos [Folhas e ramos de brócolos (Brassica oleracea var. italica L); de mamona (Ricinus communis L.); de mandioca (Manihot esculenta Crantz) e de eucalipto (Eucalyptus grandis Hill ex Maiden)].

Os materiais orgânicos frescos (folhas + ramos) foram triturados manualmente e posteriormente incorporados ao solo Latossolo Vermelho-Escuro fase arenosa, contido na câmara de vidro com volume de $3 \mathrm{~L}$ e diâmetro de $14 \mathrm{~cm}$, na proporção de $1,0 \mathrm{Kg} / \mathrm{m}^{2}$ de forma que proporcionou uma altura de $15 \mathrm{~cm}$, perfazendo um volume de 2,3 L.

Os fungos, provenientes da micoteca do DPV/FCA/UNESPBotucatu-SP, foram cultivados em meio de Batata-Dextrose-Ágar (BDA) + oxitetraciclina $(0,05 \mathrm{mg} / \mathrm{mL})$ e posteriormente transferidos para os substratos específicos, objetivando produzir as estruturas de resistência (clamidósporos e escleródios), as quais foram acondicionadas em bolsa de náilon, e enterradas no solo contido no vidro, a $10 \mathrm{~cm}$ de profundidade.

Para F. oxysporum f. sp. lycopersici Raça 2, foi adotada a metodologia de Bueno (3) que consistiu em multiplicar o fungo em meio líquido de extrato de malte, em ausência de luz, a $25^{\circ} \mathrm{C}$, por 7 dias. Após crescimento do fungo, a suspensão foi colocada em uma bandeja de alumínio, acrescentando-se pó de talco na proporção 2:1 (v/p) e deixando-se para secar em estufa de circulação forçada de ar a $26^{\circ} \mathrm{C}$ por 14 dias, condição esta que propicia a formação de clamidósporos.

O fungo M. phaseolina foi cultivado em frasco contendo substrato areno-orgânico (14) composto de três partes de esterco curtido, uma parte de areia lavada e $2 \%$ de aveia (v/p), onde foram adicionados 20 $\mathrm{mL}$ de água destilada para cada $100 \mathrm{~mL}$ de substrato. O substrato foi autoclavado duas vezes, em intervalos de 24 horas, durante uma hora a $120^{\circ} \mathrm{C}$. Posteriormente, em câmara asséptica, foram transferidos três discos de $5 \mathrm{~mm}$ de diâmetro retirados das bordas das colônias do fungo em crescimento, para os referidos frascos. Estes foram mantidos em estufa tipo BOD, a $32^{\circ} \mathrm{C}$, em ausência de luz, por quinze dias, o que condicionou a formação dos microescleródios.

O fungo $R$. solani, após crescimento em meio BDA, foi transferido para o substrato areno-orgânico (14) conforme metodologia descrita para M. phaseolina para a obtenção dos microescleródios, diferindo apenas na temperatura de incubação do fungo que foi de $25^{\circ} \mathrm{C}$.

A multiplicação de S. rolfsii foi feita de acordo com Bueno (3), transferindo um escleródio para placa contendo uma fina camada de meio BDA + oxitetraciclina $(0,05 \mathrm{mg} / \mathrm{mL})$ e incubando em estufa tipo BOD a $25^{\circ} \mathrm{C}$, no escuro, por 30 dias, até a formação completa dos escleródios, os quais foram removidos com auxílio de pincel de cerdas macias.

Após a produção dos clamidósporos e escleródios dos fungos, os mesmos foram colocados em bolsas de tecido sintético (náilon), identificadas e contendo, separadamente, cada uma 10 gramas do substrato infestado com estruturas dos fungos $F$. oxysporum $\mathrm{f}$. sp. lycopersici Raça 2, M. phaseolina e R. solani. Para S. rolfsii, cada bolsa recebeu aproximadamente 100 escleródios. As mesmas foram amarradas com linha de náilon e identificadas. Posteriormente, cada bolsa contendo cada fungo foi enterrada no solo contido nas câmaras, a $10 \mathrm{~cm}$ de profundidade, procedendo, a seguir, o fechamento com tampa de rosca e vedada com borracha de silicone.

O delineamento experimental correspondeu a seis tratamentos (Solarizado; Solarizado+Brócolos; Solarizado+Eucalipto; Solarizado+Mamona; Solarizado+Mandioca e Laboratório). Cada tratamento consistiu de oito câmaras destrutivas, contendo cada uma, os quatro fungos em bolsas de náilon separadas, sendo estas retiradas a cada dia de avaliação.

As avaliações para determinar a sobrevivência dos fungos foram realizadas aos 0, 7, 14, 21 e 28 dias após a instalação do experimento, através do plaqueamento em meio de cultura semi-seletivo, propiciando o desenvolvimento dos fungos, o que possibilitou a quantificação destes mediante a contagem das colônias formadas. Para cada bolsa, contendo os fungos, foram utilizadas cinco placas e para a análise estatística foram somados os resultados das duas bolsas do tratamento, a cada dia de avaliação.

Após a retirada das câmaras de vidro e, antes do plaqueamento em meio semi-seletivo, as bolsas com os fungos M. phaseolina, $R$. solani e $S$. rolfsii foram submetidas a uma desinfestação superficial (3) para diminuir os contaminantes e possibilitar a contagem dos sobreviventes. Dez porções do substrato contendo as estruturas de resistência ou dez escleródios, no caso de $S$. rolfsii, foram transferidos para cada uma das cinco placas (repetições), as quais foram mantidas em BOD, à temperatura ótima de crescimento para cada fungo. O substrato contendo F. oxysporum f. sp. lycopersici Raça 2 foi submetido a uma diluição seriada antes do plaqueamento (3).

O meio de cultura utilizado para avaliar a sobrevivência de $F$. oxysporum f. sp. lycopersici Raça 2 foi o semi-seletivo de Komada (12). O meio semi-seletivo RB (5) modificado que consistiu de $39 \mathrm{~g}$ de BDA, $224 \mathrm{mg}$ i.a de metalaxyl, $100 \mathrm{mg}$ de rifampicina e $1 \mathrm{~L}$ de água destilada foi usado para M. phaseolina. O fungo R. solani AG4 HGI foi avaliado em meio de KHMP (11) e S. rolfsii em meio BDA + 0,05 $\mathrm{mg} / \mathrm{mL}$ de oxitetraciclina (3).

O referencial de controle da sobrevivência das estruturas dos fitopatógenos estudados, removidos do microcosmo, foi estabelecido pelo plaqueamento concomitantemente com as estruturas dos mesmos patógenos mantidas em condições de laboratório.

A análise do número de colônias de F. oxysporum f. sp. lycopersici Raça 2 e da porcentagem média de sobreviventes de M. phaseolina, $R$. solani e $S$. rolfsii, considerando tratamentos e períodos de avaliação, foi realizada pela técnica da análise de variância não-paramétrica para o modelo com dois fatores, complementada com os respectivos testes de comparações múltiplas (24). Os resultados foram apresentados por meio da mediana (medida de tendência central) e semi-amplitude total (medida de variabilidade).

Os dados apresentados correspondem à média dos dois experimentos separados no tempo, isto foi possível uma vez que os dados obtidos mostraram consistente semelhança. 


\section{RESULTADOS E DISCUSSÃO}

Fusarium oxysporum f. sp. lycopersici Raça 2

Os dados apresentados na Figura 1 e Tabela 1 demonstram a inativação do fungo $F$. oxysporum f. sp. lycopersici Raça 2 quando se associa a incorporação de material orgânico com a simulação da solarização (microcosmo). No entanto, no tratamento onde apenas simulou a solarização, isoladamente, não ocorreu a inativação do fungo. Resultados semelhantes foram obtidos por Dias (7) e Souza \& Bueno (23) em condições de campo.

Isto reforça as divergências sobre a efetividade do uso da técnica de solarização do solo, quando aplicada de maneira isolada, no controle de formae speciales de Fusarium oxysporum (22).

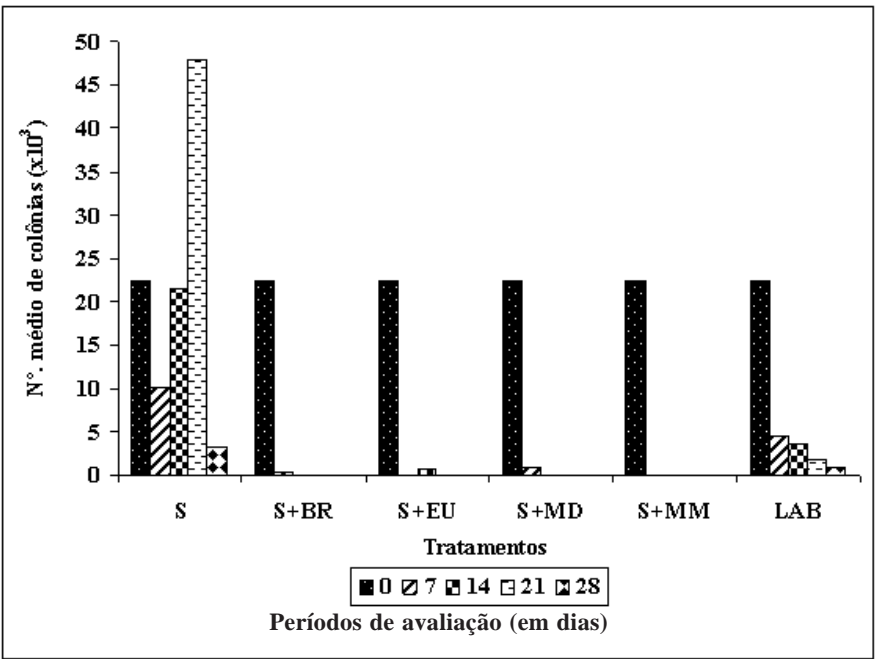

Figura 1. Sobrevivência (média de dois ensaios) de Fusarium oxysporum f. sp. lycopersici Raça 2 em simulação de solarização (microcosmo) e em laboratório. $\mathrm{S}=$ Solo; $\mathrm{BR}=$ Brócolos; $\mathrm{EU}=$ Eucalipto; $\mathrm{MD}=$ Mandioca; $\mathrm{MM}=$ Mamona; $\mathrm{LAB}=$ Laboratório.

Todos os tratamentos onde associou-se as técnicas (incorporação de materiais e simulação da solarização) houve erradicação significativa das estruturas do fungo aos 28 dias de tratamento. No entanto, a incorporação de mamona em associação com a simulação da solarização propiciou erradicação significativa do fungo já aos 14 dias de tratamento, enquanto que a incorporação de mandioca mais a simulação da solarização permitiu total controle do fungo aos 21 dias (Figura 1 e Tabela 1).
Os materiais usados na incorporação (brócolos, eucalipto, mamona e mandioca) apresentam compostos altamente fungitóxicos, alguns já conhecidos, outros ainda não identificados.

Vários trabalhos $(1,2,8)$ utilizando-se de espécies de brássicas já foram referidos e muitos dos seus compostos, oriundos da decomposição acelerada, já foram indicados como responsáveis pela inativação de fitopatógenos. No entanto, existem grandes diferenças quanto a qualidade e quantidade dos compostos entre as espécies de brássicas.

No eucalipto, Salgado et al. (21) demonstraram que há diferenças entre as substâncias presentes nas diferentes espécies, existindo, porém, compostos altamente fungitóxicos em algumas espécies e ausentes em outras.

Sendo assim, futuras pesquisas com esses materiais que apresentaram resultados efetivos devem ser feitas a fim de determinar quais compostos são responsáveis pelo real controle do patógeno, bem como a possível dosagem para a inativação desses microrganismos.

Com relação ao fungo mantido em laboratório, foi constatada diminuição gradativa na sua sobrevivência (Figura 1 e Tabela 1), fato esse também observado por Souza \& Bueno (23).

No tratamento que apenas simulou a solarização, observou-se uma queda e subseqüente aumento na sobrevivência do patógeno (Figura 1 e Tabela 1). Este aspecto foi observado por Souza \& Bueno (23), em condições de campo, exceto nos tratamentos solarizado mais a incorporação de couve e no tratamento de laboratório. Uma hipótese para explicar a oscilação é que o local do fungo (tratamento) não foi suficiente para controlar o mesmo, mas pode ter causado um efeito fungistático, tornando-o, por algum tempo, latente.

\section{Macrophomina phaseolina}

De acordo com os dados da Figura 2 e Tabela 2, observou-se também que a associação da simulação de solarização com a prévia incorporação de material orgânico propiciou o controle de $M$. phaseolina.

Em todos os tratamentos onde houve associação das técnicas, a inativação significativa das estruturas do fungo ocorreu a partir dos 21 dias de tratamento (Figura 2 e Tabela 2). Esse resultado está em concordância com os apresentados por Ambrósio et al. (1), que também obtiveram inativação de $M$. phaseolina quando associou incorporação de brócolos com solarização, mas antes dos 21 dias de tratamento. A diferença no tempo de controle pode ser devido à quantidade de material orgânico incorporado ao solo $\left(4 \mathrm{Kg} / \mathrm{m}^{2}\right)$ no trabalho de Ambrósio et al. (1), que foi superior ao utilizado no presente trabalho. No presente

Tabela 1. Mediana e semi-amplitude total do número de sobreviventes de Fusarium oxysporum f. sp. lycopersici Raça 2, conforme tratamento e época de coleta do experimento em microcosmo simulando a solarização do solo.

\begin{tabular}{|c|c|c|c|c|c|c|c|c|}
\hline \multirow{2}{*}{ Tratamentos } & \multicolumn{7}{|c|}{ Época de coleta (dias) } & \multirow{2}{*}{$\begin{array}{l}\text { Resultado do teste } \\
\text { estatístico(P- Valor) }\end{array}$} \\
\hline & 07 & & 14 & & 21 & & 28 & \\
\hline S & $10975 \pm 4875^{1,2}$ & $\mathrm{C} A B$ & $17750 \pm 17000$ & b BC & $50750 \pm 33500$ & с C & $3575 \pm 2225$ b A & $\mathrm{P}<0,01$ \\
\hline S+BR & $298 \pm 426$ & ab B & $0 \pm 1$ & a A & $2 \pm 2$ & a A & $0 \pm 0 \quad$ a $A$ & $\mathrm{P}<0,01$ \\
\hline $\mathrm{S}+\mathrm{MD}$ & $727 \pm 445$ & b $\quad \mathrm{c}$ & $3 \pm 2$ & a B & $0 \pm 1$ & a $\mathrm{A}$ & a A & $\mathrm{P}<0,01$ \\
\hline $\mathrm{S}+\mathrm{EU}$ & $23 \pm 20$ & a $B$ & $600 \pm 325$ & b $\mathrm{C}$ & $1 \pm 1$ & a A & a $\mathrm{A}$ & $\mathrm{P}<0,01$ \\
\hline $\mathrm{S}+\mathrm{MM}$ & $23 \pm 16$ & a $\mathrm{B}$ & $0 \pm 1$ & a A & $0 \pm 1$ & a A & a A & $\mathrm{P}<0,01$ \\
\hline LAB & $4575 \pm 2400$ & c C & $3625 \pm 1025$ & b $\mathrm{BC}$ & $1400 \pm 1725$ & $\mathrm{~b} A B$ & $800 \pm 325$ & $\mathrm{P}<0,01$ \\
\hline
\end{tabular}

Resultado do teste estatístico(P - Valor)
$\mathrm{P}<0,01 \quad \mathrm{P}<0,01$

$\mathrm{P}<0,01$

$\mathrm{P}<0,01$

S=Solo; BR=Brócolos; EU=Eucalipto; MD=Mandioca; MM=Mamona e LAB=Laboratório.

Medianas seguidas pela mesma letra maiúscula na linha e minúscula na coluna, não diferem entre si pelo teste de

comparações múltiplas a 5\% de probabilidade; ${ }^{2}$ Média de dois experimentos. 
Tabela 2. Mediana e semi-amplitude total do número de sobreviventes de Macrophomina phaseolina, conforme tratamento e época de coleta do experimento em microcosmo simulando a solarização do solo.

\begin{tabular}{|c|c|c|c|c|c|}
\hline \multirow{2}{*}{ Tratamentos } & \multicolumn{4}{|c|}{ Época de coleta (dias) } & \multirow{2}{*}{$\begin{array}{l}\text { Resultado do teste } \\
\text { estatístico(P- Valor) }\end{array}$} \\
\hline & 07 & 14 & 21 & 28 & \\
\hline S & $10,0 \pm 0,0^{1,2}$ a $\mathrm{A}$ & $10,0 \pm 0,0 \mathrm{~b} \mathrm{~A}$ & $10,0 \pm 0,0$ с $\mathrm{A}$ & $10,0 \pm 0,5$ b A & $\mathrm{P}>0,05$ \\
\hline S+MD & $10,0 \pm 0,0$ & $5,0 \pm 0,5$ а $\mathrm{B}$ & $0,0 \pm 0,5$ а $\mathrm{A}$ & $0,0 \pm 0,0$ a $\mathrm{A}$ & $\mathrm{P}<0,01$ \\
\hline $\mathrm{S}+\mathrm{EU}$ & $10,0 \pm 0,0$ & $10,0 \pm 0,0$ b B & $9,5 \pm 0,5$ с В & $0,0 \pm 0,0$ a $\mathrm{A}$ & $\mathrm{P}<0,01$ \\
\hline $\mathrm{S}+\mathrm{MM}$ & $10,0 \pm 0,0$ & $5,0 \pm 0,5$ a $B$ & $5,0 \pm 0,5$ b B & $0,0 \pm 0,0$ a $\mathrm{A}$ & $\mathrm{P}<0,01$ \\
\hline $\begin{array}{l}\text { Resultado do teste } \\
\text { estatístico (P - Valor) }\end{array}$ & $\mathrm{P}>0,05$ & $\mathrm{P}<0,01$ & $\mathrm{P}<0,01$ & $\mathrm{P}<0,01$ & \\
\hline
\end{tabular}

S=Solo; BR=Brócolos; EU=Eucalipto; MD=Mandioca; MM=Mamona e LAB=Laboratório.

${ }^{1}$ Medianas seguidas pela mesma letra maiúscula na linha e minúscula na coluna, não diferem entre si pelo teste de comparações múltiplas a $5 \%$ de probabilidade; ${ }^{2}$ Média de dois experimentos.

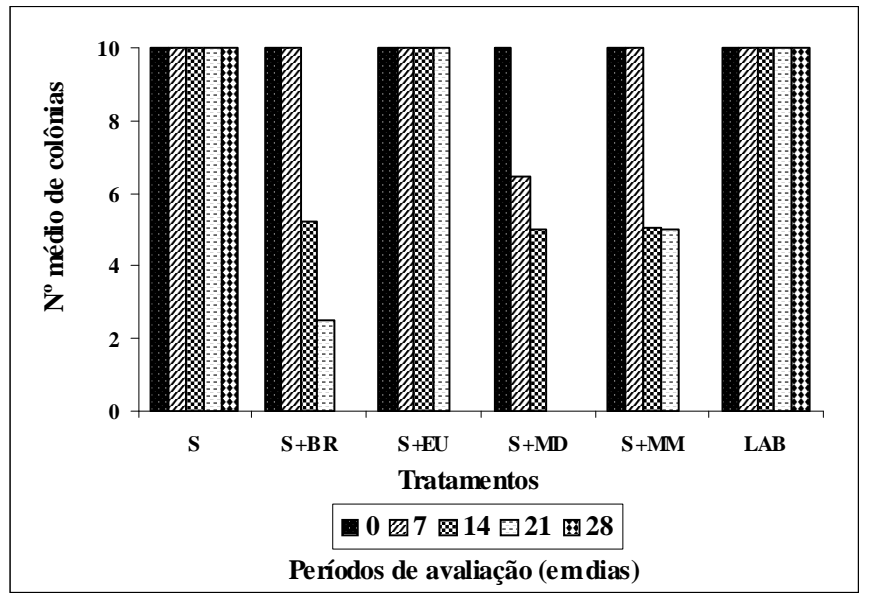

Figura 2. Sobrevivência (média de dois ensaios) de Macrophomina phaseolina em simulação de solarização (microcosmo) com diferentes tratamentos e em laboratório. S= Solo; BR= Brócolos; EU= Eucalipto; $\mathrm{MD}=$ Mandioca; $\mathrm{MM}=$ Mamona e LAB= Laboratório.

trabalho, a inativação do fungo ocorreu a partir dos 21 dias de tratamento, no microcosmo, onde incorporou-se $1 \mathrm{Kg} / \mathrm{m}^{2}$ de material orgânico. O controle nesse caso deve-se, provavelmente, a obtenção de um ambiente hermético, não havendo, portanto, perda de voláteis para o ambiente.

Os materiais brócolos, eucalipto, mamona e mandioca, certamente, formaram voláteis fungitóxicos para o fungo, quando incorporados ao solo e submetidos a simulação da solarização.

A decomposição acelerada de brássicas no solo libera compostos tóxicos, entre eles aldeídos, enxofre, isotiocianatos e glucosinolatos, que apresentam reconhecida atividade biocida para os fitopatógenos $(2,8,17,18)$. Trabalhando com brássicas, Rosa et al. (20) relataram que existem aproximadamente 20 diferentes tipos de glucosinolatos comumente encontrados em brássicas, sendo que estes apresentam atividade biocida.

A mandioca brava contém alto teor de glicosídeos cianogênicos, componentes estes que podem ter contribuído para inativação de $M$. phaseolina (6). No presente trabalho, a incorporação de mandioca com simulação da solarização foi o único tratamento que erradicou significativamente as estruturas do fungo M. phaseolina aos 21 dias de tratamento (Figura 2 e Tabela 2).

Propriedades fungitóxicas do extrato de mamona sobre
Colletotrichum gloeosporioides foram detectados por Ribeiro \& Bedendo (19), que observaram a redução do desenvolvimento e na esporulação do patógeno. Hilal et al. (10) citam como presentes nas folhas de mamona algumas classes de substâncias como glicósideos, alcalóides, triterpenos, saponinas, flavonóides e taninos. As folhas e sementes contêm alcalóides e toxialbumina (ricina) (16). Portanto, várias substâncias podem estar contribuindo para o controle do fungo.

Folhas de eucalipto apresentam óleos essenciais (misturas de eucaliptol ou cineol), terpineol, álcoois, aldeídos e terpenos. Esses compostos também podem apresentar atividade fungitóxica. Salgado et al. (21), trabalhando com espécies de eucalipto no controle de três patógenos diferentes, obtiveram resultados bastante satisfatórios, já que, indicaram haver diferentes potenciais fungitóxicos nos óleos essenciais extraídos de diferentes espécies de eucalipto.

O fungo $M$. phaseolina é de difícil controle. No entanto, esse trabalho mostrou resultados promissores quanto à sua inativação. Os quatro materiais orgânicos utilizados previamente a simulação da solarização apresentaram resultados promissores. Como este fitopatógeno tem ocorrência efetiva em regiões quentes e secas, o trabalho propiciou a prospecção de opções de materiais orgânicos a serem utilizados também nessas regiões.

\section{Rhizoctonia solani AG-4 HGI}

A Figura 3 e a Tabela 3 indicam que o fungo $R$. solani foi significativamente inativado aos 14 dias de tratamento quando associou-se incorporação de material orgânico com a simulação da solarização, com destaque para o tratamento onde incorporou-se a mandioca, já que, na primeira avaliação, 7 dias após a instalação do experimento, as estruturas do fungo encontravam-se totalmente inativadas. Possivelmente, esse patógeno apresenta grande sensibilidade aos compostos tóxicos presentes nesse material orgânico testado, fato esse de grande importância para o controle do mesmo. Portanto, a mandioca apresenta-se como um material orgânico bastante promissor, e que deve ser estudado com mais ênfase.

O efeito da solarização no controle de doenças causadas por patógenos veiculados pelo solo pode ser potencializado pela incorporação de material orgânico. Essa condição propicia a degradação acelerada do material, levando a produção de compostos tóxicos, tanto na fase líquida como na gasosa (23). É significativo o número de trabalhos atestando a efetividade do emprego da solarização associada à incorporação de materiais orgânicos (fresco ou seco) das mais variadas fontes, no controle de vários fitopatógenos do solo $(1,15,23)$. Portanto, 
Tabela 3. Mediana e semi-amplitude total do número de sobreviventes de Rhizoctonia solani AG-4 HGI, conforme tratamento e época de coleta do experimento em microcosmo simulando a solarização do solo.

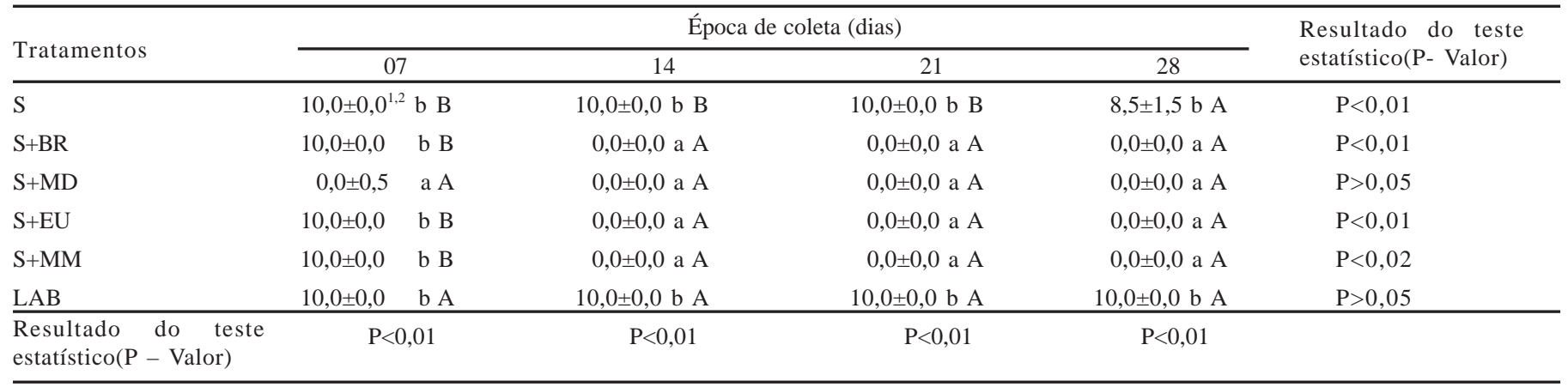

S= Solo; $\mathrm{BR}=$ Brócolos; EU= Eucalipto; $\mathrm{MD}=$ Mandioca; $\mathrm{MM}=$ Mamona e LAB= Laboratório.

${ }^{1}$ Medianas seguidas pela mesma letra maiúscula na linha e minúscula na coluna, não diferem entre si pelo teste de comparações múltiplas a $5 \%$ de probabilidade; ${ }^{2}$ Média de dois experimentos.

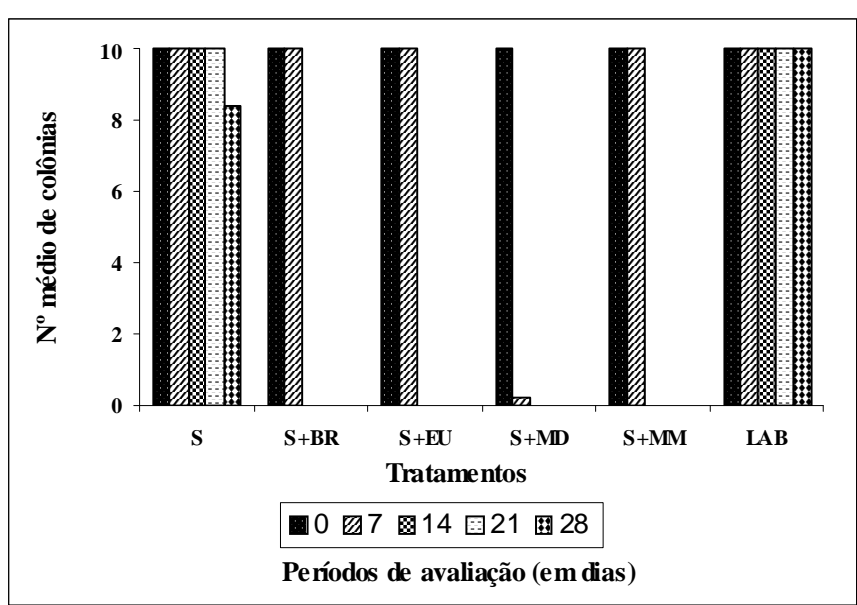

Figura 3. Sobrevivência (média de dois ensaios) de Rhizoctonia solani AG-4 HGI em simulação de solarização (microcosmo) com diferentes tratamentos e em laboratório. S= Solo; BR= Brócolos; EU= Eucalipto; $\mathrm{MD}=$ Mandioca; $\mathrm{MM}=$ Mamona e $\mathrm{LAB}=$ Laboratório.

surge a necessidade de novos trabalhos, que busquem alternativas de materiais que sejam efetivos para um grande número de patógenos e que possam ser encontrados em diversas regiões, principalmente, onde os mesmos ocorrem com freqüência.

No tratamento representativo da solarização, isoladamente, não ocorreu à morte do patógeno, embora tenha sido observada diminuição dos sobreviventes somente aos 28 dias (Figura 3 e Tabela 3). O controle de $R$. solani, através da solarização do solo, tem apresentado resultados inconsistentes, já que diferentes pesquisadores demonstram controle desse patógeno, quando submetido à técnica de solarização do solo $(13,22)$.

\section{Sclerotium rolfsii}

Nos tratamentos onde foram incorporadas as matérias orgânicas, previamente à simulação da solarização, ocorreu inativação significativa de S. rolfsii (Figura 4 e Tabela 4) aos 28 dias de tratamento.

No tratamento onde apenas foi simulado a solarização não ocorreu a morte do patógeno (Figura 4 e Tabela 4), como relatado também por Souza \& Bueno, (23).

Nos tratamentos onde associou-se à incorporação de brócolos, mandioca e mamona com o microcosmo (simulação da solarização) houve uma diminuição gradativa na sobrevivência de $S$. rolfsii ao longo das épocas de coleta. Entretanto, o tratamento onde adicionou-se o eucalipto com a solarização, embora tenha sido eficiente no controle do patógeno, não houve a morte gradativa, sendo que a inativação do fungo somente se deu aos 28 dias de tratamento (Figura 4 e Tabela 4). Isto deve-se, provavelmente, ao fato de que cada material, quando incorporado, libera vários compostos, sendo que eles podem apresentar maior ou menor grau de toxicidade para determinado microrganismo.

Portanto, existem aberturas para novos trabalhos, dentro dessa linha de pesquisa, que possam diferenciar o efeito tóxico de cada material em relação aos fitopatógenos veiculados pelo solo. Os materiais com poder fungitóxico, ainda que mesmo dentro do mesmo gênero, apresentam diferenças quantitativas e qualitativas dos compostos produzidos. Sendo assim, é de suma importância que trabalhos futuros relatem a relação desses materiais com os patógenos, já que existem materiais que, quando incorporados, podem ser tóxicos para alguns microrganismos e não para outros, bem como, podem, ainda, apresentarem diferentes graus de toxicidade, considerando os diferentes patógenos estudados.

A associação da incorporação de materiais orgânicos com a solarização do solo tem sido apresentada como uma forma de controle bastante eficiente na inativação de patógenos que apresentam difícil erradicação. Além disso, essa técnica diminui, drasticamente, o tempo necessário para o tratamento, permitindo ao produtor a utilização da área mais precocemente, e, também, pode ser considerada uma forma de melhorar o estado nutricional do solo.

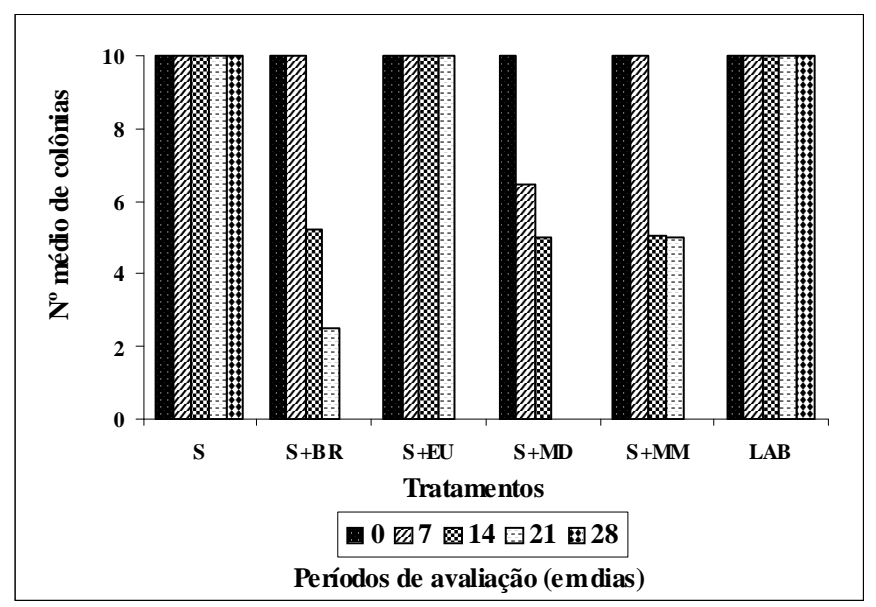

Figura 4. Sobrevivência (média de dois ensaios) de Sclerotium rolfsii em simulação de solarização (microcosmo) com tratamentos diferentes e em laboratório. $\mathrm{S}=$ Solo; $\mathrm{BR}=$ Brócolos; $\mathrm{EU}=$ Eucalipto; $\mathrm{MD}=$ Mandioca; $\mathrm{MM}=$ Mamona e LAB= Laboratório. 
Tabela 4. Mediana e semi-amplitude total do número de sobreviventes de Sclerotium rolfsii, conforme tratamento e época de coleta do experimento em microcosmo simulando a solarização do solo.

\begin{tabular}{|c|c|c|c|c|c|}
\hline \multirow[t]{2}{*}{ Tratamentos } & \multicolumn{4}{|c|}{ Época de coleta (dias) } & \multirow{2}{*}{$\begin{array}{c}\text { Resultado do teste } \\
\text { estatístico (P- Valor) }\end{array}$} \\
\hline & 07 & 14 & 21 & 28 & \\
\hline S & $10,0 \pm 0,0^{1,2}$ b A & $10,0 \pm 0,0$ b A & $10,0 \pm 0,0 \mathrm{~b} \mathrm{~A}$ & $10,0 \pm 0,0$ b A & $\mathrm{P}>0,05$ \\
\hline $\mathrm{S}+\mathrm{MD}$ & $6,5 \pm 1,5$ a $\mathrm{B}$ & $5,0 \pm 0,0$ a $\mathrm{B}$ & $5,0 \pm 0,5$ a $\mathrm{B}$ & $0,0 \pm 0,0$ a $\mathrm{A}$ & $\mathrm{P}<0,01$ \\
\hline $\mathrm{S}+\mathrm{EU}$ & $10,0 \pm 0,0 \quad$ b B & $10,0 \pm 0,0$ b B & $10,0 \pm 0,0$ b B & $0,0 \pm 0,0$ a $\mathrm{A}$ & $\mathrm{P}<0,01$ \\
\hline $\mathrm{S}+\mathrm{MM}$ & $10,0 \pm 0,0$ & $5,0 \pm 0,5$ а $B$ & $5,0 \pm 0,0$ a $\mathrm{B}$ & $0,0 \pm 0,0$ a $\mathrm{A}$ & $\mathrm{P}<0,01$ \\
\hline
\end{tabular}

\begin{tabular}{lllll}
\hline Resultado do teste & $\mathrm{P}<0,01$ & $\mathrm{P}<0,01$ & $\mathrm{P}<0,01$ & $\mathrm{P}<0,01$
\end{tabular}

estatístico(P - Valor)

$\mathrm{S}=$ Solo; $\mathrm{BR}=$ Brócolos; EU= Eucalipto; $\mathrm{MD}=$ Mandioca; $\mathrm{MM}=$ Mamona e LAB= Laboratório.

${ }^{1}$ Medianas seguidas pela mesma letra maiúscula na linha e minúscula na coluna, não diferem entre si pelo teste de comparações múltiplas a 5\% de probabilidade; ${ }^{2}$ Média de dois experimentos

O uso do microcosmo tem propiciado uma idéia preliminar da potencialidade do material orgânico. Isto pode ser notado quando se compara os resultados obtidos nesse trabalho com outros realizados em condições de campo $(1,23)$. No entanto, não é uma simulação autêntica da solarização do solo, pois, em condições de microcosmo, o ambiente é totalmente hermético, não havendo, portanto, volatilização dos gases produzidos com a decomposição dos materiais. Contrariamente, quando se utiliza a solarização do solo, em condições de campo, há perda de voláteis para o ambiente e a temperatura é totalmente variável.

\section{REFERÊNCIAS BIBLIOGRÁFICAS}

1. Ambrósio, M. M. Q; Bueno, C. J.; Souza, N. L. Sobrevivência de Macrophomina phaseolina em solo incorporado com brócolos seguido de solarização. Summa Phytopathologica, Botucatu, v.30, n.3, p.364-370, 2004.

2. Blok, W. J.; Lamers, J. G., Termorshuizen, A. J., Bollen, G. J. Control of soilborne plant pathogens by incorporating fresh organic amendments followed by tarping. Phytopathology, St. Paul, v.90, n.3, p.253-259, 2000.

3. Bueno, C. J.; Ambrósio, M. M. Q.; Souza, N. L. Produção e avaliação da sobrevivência de estruturas de resistência de fungos fitopatogênicos habitantes do solo. Summa Phytopathologica, Botucatu, v.33, n.1, p.47-55, 2007.

4. Bueno, C. J.; Ambrósio, M. M. de Q.; Souza, N. L. de.; CEREZINI, P. C. Controle de Fusarium oxysporum f.sp. lycopersici raça 2, Macrophomina phaseolina e Sclerotium rolfsii em microcosmo simulando solarização com prévia incorporação de couve (Brassicae oleracea var. acephala L.). Summa Phytopathologica, Botucatu, v.30, n.3, p.356-363, 2004.

5. Cloud, G. L. Comparison of three media for enumeration of sclerotia of Macrophomina phaseolina. Plant Disease, St. Paul, v.75, n.8, p.771-772, 1991.

6. Conceição, A. J. da. A mandioca. São Paulo: Nobel, 1987, 382p.

7. Dias, M. S. C. Efeito da solarização do solo no controle da morte prematura de maracujazeiros. Botucatu, 1997. $125 \mathrm{f}$. Tese (Doutorado em Agronomia/Horticultura) - Faculdade de Ciências Agronômicas, Universidade Estadual Paulista, Botucatu.

8. Gamliel, A.; Stapleton, J. J. Characterization of antifungal volatile compounds envolved from solarizes soil amended with cabbage residues. Phytopathology, St. Paul, v.83, p.899-905, 1993.

9. Ghini, R. Alternativas para substituir o brometo de metila na agricultura. Summa Phytopathologica, Jaboticabal, v.27, n.1, p.162, 2001.

10. Hilal, S. H.; Haggag, M. Y.; Reda, M. Phytochemical Study of
Ricinus communis L. Egyptian Journal Pharmaceutical Science, Cairo, v.20, n.1/4, p.63-70, 1979.

11. Ko, W.; Hora, F. K. A selective medium for Rhizoctonia solani in soil. Phytopathology, St. Paul, v.61, n.6, p.707-710, 1971.

12. Komada, H. Development of a selective medium for quantitative isolation of Fusarium oxysporum from natural soil. Review of Plant Protection Research, Tokyo, v.8, p.114-124, 1975.

13. Lee, F. N. Effect of soil solarization with clear plastic and shallow flood on the survival of Rhizoctonia solani sclerotia. Phytopathology, St. Paul, v.75, p.1291, 1985. (Abstract).

14. Lefèvre, A. F.; Souza, N. L. de. Determinação da temperatura letal para Rhizoctonia solani e Sclerotium rolfsii e efeito da solarização sobre a temperatura do solo. Summa Phytopathologica, Jaguariúna, v.19, n.2, p.107-112, 1993.

15. Pinkerton, J. N.; Ivors, K. L.; Miller, M. L.; Moore, L. W. Effect of soil solarization and cover crops on populations of selected soilborne plant pathogens in wester Oregon. Plant Disease, St. Paul, v.84, n.9, p.952-960. 2000.

16.Plantas tóxicas. Disponível em: <http:// aquabiotech2.tripod.com/id5.-html $>$ Acesso em: 17 maio 2005.

17. Ramirez-Villapudua, J.; Munnecke, D. E. Control of cabage yellow (Fusarium oxysporum f. sp. Conglutinans) by solar heating of field soils amended with cabbage residues. Plant disease, St. Paul, v.78, n.3, p.217-221, 1987.

18. Ramirez-Villapudua, J.; Munnecke, D. E. Control of cabbage yellows (Fusarium oxysporum f.sp. couglutinans) by solar heating of field soil amended with dry cabbage residues. Plant Disease, St. Paul, v.78, p.289-295, 1988.

19. Ribeiro, L. F.; Bedendo, I. P. Efeito Inibitório de extratos vegetais sobre Colletotrichum gloeosporioides - Agente causal da podridão de frutos de mamoeiro. Scientia Agrícola, v.56, n.4, p.1267-1271, 1999.

20. Rosa, E. A. S.; Heaney, R. K.; Fenwick, G. R. Glucosinolates in crop plants. Horticultural Reviews, New York, v.19, p.99215, 1997.

21. Salgado, A. P. S. P.; Cardoso, M. G.; Souza, P. E.; Souza, J. A.; Abreu, C. M.; Pinto, J. E. B. P. Avaliação da atividade fungitóxica de óleos essenciais de folhas de Eucalyptus sobre Fusarium oxyporum, Botrytis cinerea e Bipolaris sorokiniana. Ciências Agrotécnicas, Lavras, v.27, n.2, p.249-254, 2003.

22. Souza, N. L. Solarização do solo. Summa Phytopathologica, Jaguariúna, v.20, n.2, p.3-15, 1994.

23. Souza, N. L.; Bueno, C. J. Sobrevivência de clamidósporos de Fusarium oxysporum f. sp. lycopersici Raça 2 e Sclerotium rolfsii em solo solarizado incorporado com matéria orgânica. Summa Phytopathologica, Botucatu, v.29, n.2, p.153-160, 2003.

24. Zar, J. H. Biostatistical analysis. New Jersey: Prentice-Hall, 1999. 663p. 